\title{
A Comprehensive Review on Covid-19
}

\author{
Seyyed Hossein Hassanpour (iD) ${ }^{1, *}$ and Jafar Nikbakht ${ }^{2}$ \\ ${ }^{1}$ Department of Medicinal Chemistry, School of Pharmacy, Tehran University of Medical Sciences, Tehran, Iran \\ ${ }^{2}$ Department of Pharmacology, School of Medicine, Yasouj University of Medical Sciences, Yasouj, Iran \\ "Corresponding author: Department of Medicinal Chemistry, School of Pharmacy, Tehran University of Medical Sciences, Tehran, Iran. Email: dr.hossein1366@yahoo.com
}

Received 2020 October 12; Revised 2020 November 23; Accepted 2020 December 30.

\begin{abstract}
During the past two decades, multiple viral epidemics have emerged, including the epidemics of H1N1 influenza in 2009 and the Acute Respiratory Syndrome Coronavirus (SARS-CoV) in 2002 - 2003. Moreover, the Middle East Respiratory Syndrome Coronavirus (MERS-CoV) was initially recognized in Saudi Arabia in 2012. Recently, cases of another lower respiratory tract infection (LRTI) were discovered in Wuhan, Hubei province, China, on December 31st 2019, and reported to the WHO country office in the country. Studies in the field have referred to the identification of first symptomatic people in early December 2019. Since experts in the field could not determine the causative agent of the disease, they mistakenly categorized the first reported cases as pneumonia of unknown etiology (PUE). Therefore, the Chinese Center for Disease Control and Prevention (China CDC), as well as local CDCs, arranged a full outbreak investigation plan, ascribing the etiology to a newly discovered virus of the coronavirus (CoV) family (i.e., the causative agent of COVID-19).
\end{abstract}

Keywords: COVID-19, MERS, Pneumonia, SARS, WHO, CDC

\section{Context}

The World Health Organization (WHO) declared that viral infectious diseases are emerging and representing crucial threats to public health. During the past two decades, multiple viral epidemics, including H1N1 influenza in 2009 and SARS-CoV in 2002 - 2003, have been recorded. Moreover, MERS-CoV was initially recognized in Saudi Arabia in 2012. Most recently, cases with an unjustified lower respiratory tract infection (LRTI) were discovered in Wuhan, Hubei province, China, first announced to the WHO country office in China on December 31st, 2019. Thereafter, Tedros Adhanom Ghebreyesus on February 11th, 2020, identified the novel CoV-caused infection as the coronavirus disease-2019 (COVID-19). Apparently, the COVID-19 was highly transmissible and rapidly spread worldwide. At first, COVID-19 was termed 2019-nCoV, which was then called the SARS-CoV-2 virus by the specialists working in the International Committee on Taxonomy of Viruses (ICTV) because of its high similarity to the virus causing the SARS outbreak (SARS-CoVs). In fact, CoVs have been the main pathogens causing emerging respiratory disease outbreaks in recent decades. These viruses belong to the large families of single-stranded RNA viruses (+ssRNA), with the ability of Proliferation in diverse animal species (1). However, for reasons that should be clarified, such viruses are able to pass species barriers and create diseases from the simple common cold to more serious conditions like SARS and MERS in humans. Coronavirus are positivesense single-stranded RNA viruses known for their crownlike morphology in electron microscopy images (coronam means crown in Latin) due to the spike glycoproteins located on their envelopes. Orthocoronavirinae is a subfamily of the Coronaviridae superfamily, which is classified into four genera, including gamma-, delta-, beta-, and alphaCoVs. In addition, the genus beta-CoV has been divided into five lineages or sub-genera (2). Reportedly, $2 \%$ of healthy people are carriers of at least one coronavirus, and COVs are responsible for approximately $5-10 \%$ of acute respiratory tract infectious diseases (3). Common HCoVs, including HCoV-HKU1, HCoV-OC43, HCoV-229E, and HCoV-NL63, develop self-limiting upper respiratory tract infections and common colds in immuno-competent people. Other HCoVs, including MERS-CoV, SARS-CoV, and SARS$\mathrm{CoV}-2$, are responsible for epidemic diseases causing respiratory and extra-respiratory presentations with different clinical severity. The death rates of MERS-CoV and SARSCoV have been reported to be 35 and 10\%, respectively. Accordingly, the SARS-CoV-2 virus has been classified in the genus beta-CoV, which possesses elliptic or round and predominantly pleomorphic morphology (60 to $140 \mathrm{~nm}$ in diameter). Chan et al. reported that the genome of the novel $\mathrm{HCoV}$, which was obtained from a cluster of patients presenting with atypical pneumonia after traveling 
to Wuhan, showed 89 and $82 \%$ nucleotide similarity with bat-derived SARS-like-CoVZXC21 and human-derived SARSCoV, respectively (4). The transmission of the virus is possible via aerosols in the case of prolonged exposure to a high concentration of aerosols indoors. Data from the SARS-CoV-2 virus spread in China revealed that close interpersonal contact was one of the important ways of virus transmission. In fact, the spread of the virus was mainly observed among healthcare professionals and their family members, and other close relatives. The China CDC and local CDCs investigated the first infected patients in Wuhan and found that the possible incubation period was between three and seven days, and by two weeks, and commonly 12.5 days ( $95 \% \mathrm{CI}=9.2-18$ ) from the onset of the infection, clinical symptoms appeared (5). As well, it was found that the epidemic would almost double itself every seven days, with the initial reproduction rate of 2.2 (Ro$\mathrm{R}$ naught). The likelihood of virus transmission from one patient to another was reported to be 2.2 persons on average (6). Inspired by SARS-CoV pathogenesis, SARS-CoV-2 was presumed to infect human cells via the spike glycoprotein binding to its cellular receptor, angiotensin-converting enzyme 2 (ACE2), and several critical residues in SARS-CoV-2 RBD were identified to interact with human ACE2.

The clinical manifestations of SARS-CoV-2-infected patients range from mild non-specific symptoms to severe pneumonia with organ function damage. A study by Wang et al. (7) showed that $39.6 \%$ of 140 confirmed COVID-19 patients had gastrointestinal symptoms, and $10.1 \%$ of them presented with gastrointestinal discomfort at the onset of symptoms. A fever was not necessarily observed at first, but some patients developed a fever after hospitalization. Besides, some patients with a severe disease did not even develop a fever.

\section{Epidemiology}

According to the WHO, the environmental samples taken from Huanan seafood market were tested positive for SARS-CoV-2, but the specific animals associated with the virus have not been identified. Based on previous evidence, bats, the hosts of more than 30 coronaviruses, might be the origin of COVID-19. Bats are the natural reservoirs of SARSCoV and MERS-CoV and transmit the viruses to the human through palm civets and dromedary camels, respectively. The RaTG13, which is a short RNA-dependent RNA polymerase (RdRp) from a bat coronavirus, showed the closest similarity to the respective enzyme of the SARS-CoV-2 virus with 96.2 - 98.7\% identity in the whole-genome sequence. The other two bat-derived SARS-like coronaviruses, bat-SLCoVZXC21 and bat-SL-CoVZC45, were closer to SARS-CoV-2 than SARS-CoV and MERS-CoV, showing an approximately $88 \%$ nucleotide identity. As for the intermediate hosts of
SARS-CoV-2, recent studies have suggested that pangolins are the most probable animal hosts. Two sub-lineages of SARS-CoV-2 were found in the organs of pangolins obtained from anti-smuggling activities in Guangdong and Guangxi provinces of China by metagenomic sequence analysis. Tian et al. (8) reported that SARS-CoV-2 was derived from the reorganization of a pangolin-CoV-like virus and a BatCoV-RaTG13-like virus. However, the pangolin may not be the only intermediate reservoir because SARS-CoV-2 does not originate from the pangolin-CoV-like virus directly, as demonstrated by molecular and phylogenetic analyses (3). To sum up, bats are the most probable original reservoir based on the current evidence indicating that the Wuhan Huanan seafood market was not the only origin of SARSCoV-2 based on the epidemiological analysis of 41 cases (9) Pangolins may act as one of the intermediate hosts, and more work is needed to provide precise information about the original and intermediate hosts of SARS-CoV-2.

Transmissibility is an important factor of an epidemic (10). Men made up the majority of COVID-19 patients, with a proportion of 50 - 75\% (11-13). Due to different data sources, the infection rate in medical staff has been widely variable from 2.1 to $29 \%$ (14). Approximately $25.2-50.5 \%$ of SARSCoV-2-infected patients had one or more underlying diseases, including hypertension, diabetes, chronic obstructive pulmonary disease, cardiovascular disease, and malignancy. It was also reported that the longest incubation period was 24 days. The percentage of the patients exposed to the Huanan seafood market varies between 8.7 and $66 \%$ (15). The identification of patients with no history of contact with the Huanan seafood market, as well as the spread of the virus among medical staff (16), indicated human-tohuman transmission that occurs mainly via droplets after coughing or sneezing and direct contact (5). In addition, several studies reported that the fecal-oral pathway might also be a potential way for SARS-CoV-2 transmission (17). The SARS-CoV-2 virus was also isolated from the urine of a patient in a recent study (18), but it is unclear whether or not human-to-human transmission can occur through the above routes. The basic reproduction number, Ro, an important indicator of transmission, is commonly used to estimate the average number of the secondary infections raised by one infected case in a fully susceptible population during the early phase of an outbreak (19). If Ro is higher than 1, human-to-human transmission may persist, and Ro has been estimated to range from 1.4 to 6.49 using various methods (20), indicating different data and modeling methods. Liu et al. estimated an average Ro of 3.28 with a median of 2.79 based on the analysis of 12 studies. Overall, a Ro range of 2 - 3 is indeed reliable, suggesting the potential incidence of sustained human-to-human transmission (21). Additionally, many factors can affect the Ro value, including the estimation period, as well as utilized models 
and datasets (22). As various measures have taken effect, the estimated Ro is mutable. As it was argued, it was impossible to predict what would happen at the early phases of the SARS-CoV-2 epidemic. The initial Ro estimated for SARS$\mathrm{CoV}$ was higher than 2.0, but the predicted large outbreak did not occur (23). It is also notable that asymptomatic patients can be sources of the infection (24). The supercommunicator effect is worthy of notice, referring to the individuals who can infect more than 100 persons (25). The immediate priority is to clarify all potential transmission routes. After all, the super-spreading phenomenon has a massive impact on the pandemic. Anyway, it is necessary for us to take effective measures and keep ourselves alert to control the pandemic. At this critical period, it is apparently wise to continue taking steps to control the outbreak. Coronavirus replication, SARS-CoV-2 structure, and SARS-CoV-2 RNA genome have been briefly described in Figures $1-3$.

\section{Organ Involvement in COVID-19}

In a study on 138 COVID-19 patients (7), the most common clinical features were fever (99\%), fatigue (70\%), dry cough (59\%), anorexia (40\%), myalgia (40\%), dyspnea (31\%), and sputum production (27\%). Other cohort studies have reported a similar range of clinical findings $(11,26,27)$. However, fever may not be a universal finding, and one study reported that $20 \%$ of their patients had a very lowgrade fever $\left(<100.4^{\circ} \mathrm{F} / 38^{\circ} \mathrm{C}\right)$, and another report (15) described a fever in $44 \%$ of patients. Headache, sore throat, and rhinorrhea have also been noted as less common symptoms. Although not highlighted in the aforementioned studies, anosmia and dysgeusia (smell and taste disorders) have been reported as well (28). Patients with existing cardiovascular disease (CVD) are at a greater risk of suffering from severe COVID-19 and having a poorer prognosis. A meta-analysis of 46,248 patients with confirmed COVID-19 found that the most common co-morbidities were hypertension (17\%), diabetes (8\%), and CVD (5\%) (29). Cardiovascular disease and hypertension have also been more prevalent in patients with severe vs. non-severe COVID-19 (odd ratios of 3.42 and 2.36, respectively) (29). On the other hand, it has been agreed that COVID-19 itself can also have adverse effects on cardiovascular health in patients with preexisting CVD, causing or aggravating damage to the heart. There are reports of cardiogenic involvement in patients without known CVD (30), as well as cases with solely cardiac presentations $(31,32)$. In a study by Wang et al, 7.2\% of patients had either elevated troponin levels or new electrocardiography or echocardiography abnormalities suggestive of cardiac injury (22). The enzyme ACE2 is highly expressed in the heart, providing a ground for ACE2-dependent myocardial infarction. Blood pressure abnormalities $(33,34)$ and palpitation due to arrhythmia (35) can also be seen in response to the COVID19 infection. Hu et al. and Zeng et al. also reported that these patients can develop reduced ejection fraction and heart enlargement (36). Acute kidney injury (AKI) is characterized by the abrupt loss of renal function that develops within seven days and has been observed in association with SARS and MERS-CoV (37). Although the exact pathogenesis of renal involvement in the COVID-19 infection is unclear, it is reported that AKI in COVID-19 accompanies sepsis, multiorgan failure, and shock, suggesting the cause of AKI to be acute tubular necrosis (7). Alternatively, a study based on single-cell transcriptome analysis (38) proved the expression of ACE2 receptors on real cells, suggesting the direct renal cellular damage by SARS-CoV2. A significant number of patients reported gastrointestinal (GI) symptoms such as diarrhea, nausea, vomiting, and abdominal pain, with some reporting these symptoms as their sole complaints (39). The incidence of GI symptoms, alongside the detection of SARS-CoV-2 RNA in the stool samples of infected patients (40), suggest that ACE2 receptors are highly expressed, and therefore, the GI tract is another target for the SARS-CoV-2 virus. Mild and transient liver injury, as well as severe liver damage can occur in the course of the COVID-19 infection. Wong et al. indicated that 14.8 $53.1 \%$ of COVID-19 patients had abnormal levels of ALT, AST, and bilirubin during the course of the disease, with bilirubin showing the lowest elevation. Furthermore, they reported that the severity of liver damage was proportional to the severity of COVID-19 (39-45). It has been suggested that the viral invasion of the central nervous system by the SARS-CoV2 virus is possible through the synapse-connected route, as observed in the case of other coronaviruses such as SARS-CoV, and can lead to several neurological complications including ataxia, seizures, neuralgia, unconsciousness, acute cerebrovascular disease, and encephalopathy $(46,47)$. Disseminated intravascular coagulation is another common complication of COVID-19, reported in $71.4 \%$ of non-survivors compared to only $0.6 \%$ of survivors (48).

\section{Histopathology}

In a study by Tian et al., lung histopathological data of two patients undergoing lung lobectomy for adenocarcinoma showed evidence of perioperative infection (8).

\section{The Effects of COVID-19 on Pregnant Women and Chil- dren}

Based on a publication by the Royal Australian and New Zealand College of Gynecologists and Obstetricians (RANZCOG), the following points are worth considering: (1) there is no evidence linking the COVID-19 with an elevated 


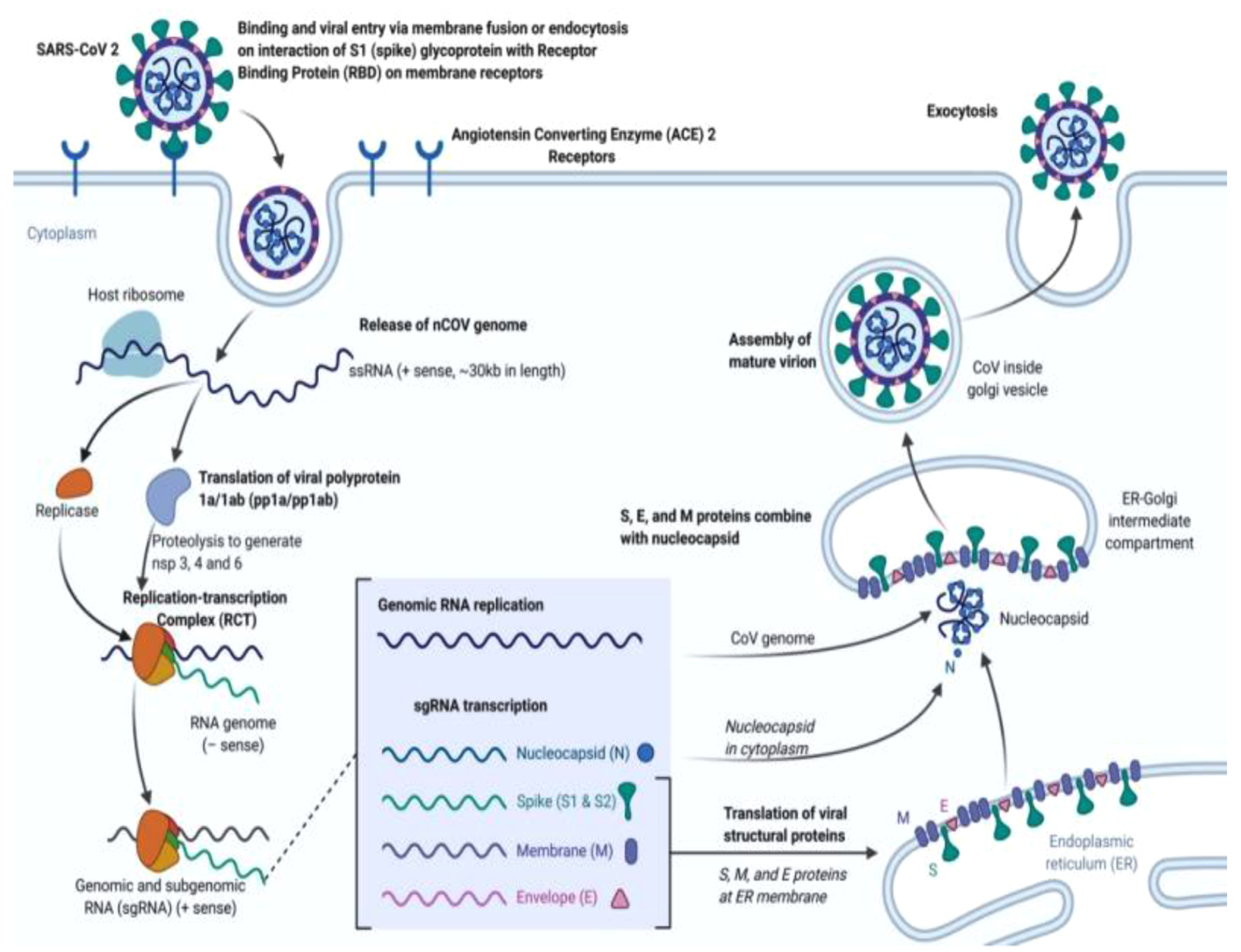

Figure 1. Coronavirus replication.

risk of miscarriage; (2) recent case reports suggest that the virus may pass from the mother to the baby (vertical transmission). However, this is very early, preliminary data that has not been confirmed. There was no evidence of harm to babies; (3) there is no evidence that COVID-19 can pass to the baby through breast milk; (4) pregnant women are advised to avoid non-essential travel and follow the instructions given to the general public.

The changes of the healthcare system in response to COVID-19 may also impact maternity care. Here are some of the changes that can be considered in hospitals: (1) reducing, postponing, and/or increasing the interval between antenatal visits; (2) shortening the duration of antenatal visits; (3) using telehealth consultation as a replacement or in parallel with routine visits; (4) avoiding face to face antenatal classes; (5) limiting visitors (partner only) while in the hospital; (6) earlier discharge from the hospital than would otherwise be planned.
Based on the current evidence regarding the impact of COVID-19 on young children, the Centers for Disease Control and Protection have advised the following: (1) based on available evidence, children do not appear to be at a higher risk of COVID-19 than adults; (2) the symptoms of COVID19 in children appear to be the same as in adults, such as fever, runny nose, cough, and in some cases, diarrhea and vomiting; (3) children with confirmed COVID-19 generally present with mild symptoms.

\section{History and Clinical Properties}

In a study, Huang et al. reported dyspnea, dry cough, malaise, and fever among 41 COVID-19 patients (11). They performed chest CT scan and found pneumonia with unjustified findings; $32 \%$ of the patients needed ICU care, and the fatality rate was 15\% (11). The JAMA, on February 24th, 2020, published the epidemiological and clinical 


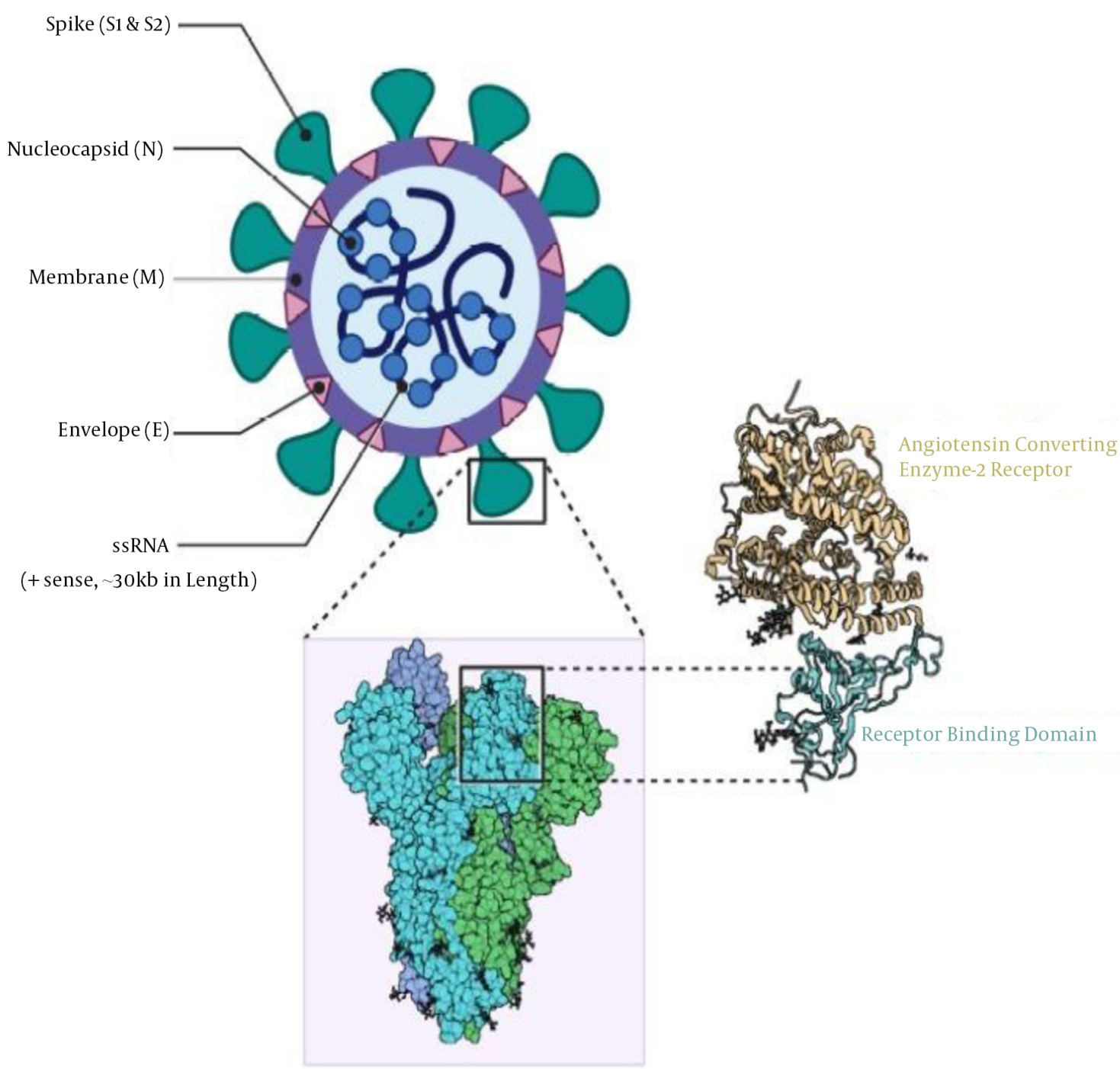

Figure 2. SARS-CoV-2 structure

data reported by the China CDC on 72,314 cases with preliminary diagnosed, asymptomatic, confirmed, and suspected COVID-19, illustrating an epidemiologic curve for the Chinese outbreak (49). Among confirmed cases who comprised $62 \%$ of the total, $1 \%$ were asymptomatic but tested positive following the viral nucleic acid test. Among the confirmed cases, the overall case-fatality rate was $2.3 \%$, and fatal cases primarily occurred in old patients aged 70 - 79 years $(8.0 \%)$ and $\geq 80$ years (about $15 \%$ ). Death occurred in $49.0 \%$ of patients with critical conditions, suffering from comorbidities such as diabetes, neoplasms, chronic respiratory disease, and cardiovascular disease. It is notable that the Chinese CDC classified COVID-19 clinical symptoms based on the severity of the disease. Mild dis- ease ( $81 \%$ of cases) can present as non-pneumonia or mild pneumonia, while severe disease ( $14 \%$ of cases) can be associated with a blood oxygen saturation $\left(\mathrm{SpO}_{2}\right)$ of $\leq 93 \%$, the respiration rate of $\geq 30 / \mathrm{min}$, dyspnea, the $\mathrm{PaO}_{2} / \mathrm{FiO}_{2}$ ratio of $<300$, and lung infiltration of $>50 \%$, which can occur within 24 - 48 hours (49). Mild COVID-19 is commonly associated with the symptoms and manifestations of a viral infection in the upper respiratory tract, such as malaise, muscular pain, sore throat, headache, nasal congestion, dry cough, and low-grade fever. Non-respiratory symptoms such as diarrhea can lead to a diagnostic challenge when compared with earlier human CoV infections. Respiratory signs like dyspnea and cough (or pediatric tachypnea) have been recorded in the absence of severe pneumo- 


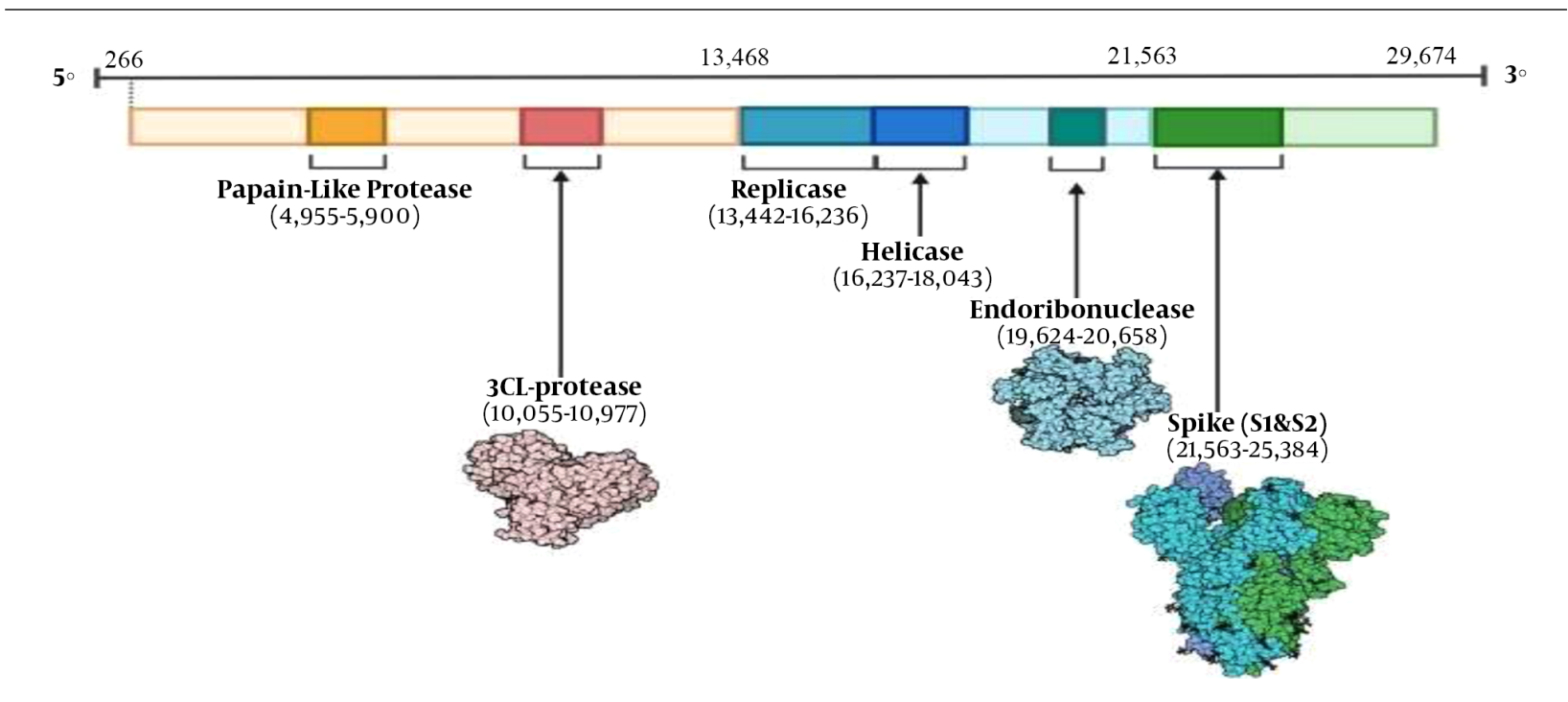

Figure 3. Single-stranded RNA genome of SARS-CoV2

nia symptoms. Other symptoms are fever, respiratory distress, severe dyspnea, tachypnea of $>30$ breaths/min, and $\mathrm{SpO}_{2}$ of $<90 \%$ on room air. It must be noted that the presence of fever should be carefully examined because even in severe or acute forms of the disease, it may be moderate or even absent. The presence of ARDS suggests either the development of a new severe respiratory failure or the worsening of a previously identified respiratory problem. Therefore, the degree of hypoxia can be used to distinguish various types of ARDS, using the $\mathrm{PaO}_{2} / \mathrm{FiO}_{2}$ ratio as a reference. Accordingly, mild ARDS presents with $200 \mathrm{mmHg}$ $<\mathrm{PaO}_{2} / \mathrm{FiO}_{2} \leq 300 \mathrm{mmHg}$ in patients without a need for ventilation or those under non-invasive ventilation using positive end-expiratory pressure or a continuous positive airway pressure of $\geq 5 \mathrm{cmH}_{2} \mathrm{O}$. Moderate ARDS is characterized with $100 \mathrm{mmHg}<\mathrm{PaO}_{2} / \mathrm{FiO}_{2} \leq 200 \mathrm{mmHg}$ while in severe $\mathrm{ARDS}, \mathrm{PaO}_{2} / \mathrm{FiO}_{2}$ is $\leq 100 \mathrm{mmHg}$. In addition, chest imaging, including chest radiograph, lung ultrasound, and CT scan, demonstrates bi-lateral opacities (lung infiltrates $>50 \%$ ), which would not be thoroughly illustrated by lobar, lung collapse, or effusion. Although clinical and imaging findings may reveal pulmonary edema in some cases, cardiac failure and other causes of this phenomenon, like fluid overload, as the initial respiratory cause of edema, should be excluded by methods such as echocardiography. The third International Consensus Definitions for Sepsis and Septic Shock (Sepsis-3) declared that sepsis may trigger life-threatening organ dysfunction due to the host's dysregulated responses to confirmed or suspicious infections (44-46). Septic shock, which has been associated with a high mortality rate, accompanies abnormal circulation, cellular damage, and metabolic disor- ders such as elevated serum lactate levels (i.e., $>2 \mathrm{mmol} / \mathrm{L}$ or $>18 \mathrm{mg} / \mathrm{dL}$ ). Since COVID-19 patients commonly suffer from persistent hypotension despite volume resuscitation, it is necessary to administer vasopressors to maintain a mean arterial pressure (MAP) of higher than or equal to $65 \mathrm{mmHg}$.

\section{Management}

For symptomatic and severely ill patients, oxygen therapy is an essential therapeutic intervention. Patients with respiratory failure who are refractory to oxygen therapy may need mechanical ventilation, and hemodynamic intervention is required to manage septic shock. Upon diagnosis of sepsis, standard care should be commenced as soon as possible, including fluid bolus therapy and the administration of vasopressors to manage hypotension. Prophylaxis against venous thromboembolism is strongly recommended. Low-molecular weight heparin (LMWH) is preferred over unfractionated heparin, as well as nonpharmacological modalities such as intermittent pneumatic compression stockings. Due to the absence of clinical evidence, there are no approved antiviral drugs against SARS-CoV-2. Remdesivir, a nucleotide analogue RNA polymerase inhibitor with a broad-spectrum antiviral activity, has been demonstrated to be effective against the Ebola virus in rhesus monkeys (47).

\section{Conclusions}

According to analyses, the incidence and spread of SARS-CoV-2 depend on the interactions of the virus with 
the human immune system, viral parameters (including the type of the virus, viral titer and load, in vitro viral viability, and the mutation rate), and host-related parameters (such as immune system competency, the patient's age, gender, and physical and nutritional conditions, genetic factors (e.g., HLA genes), and neuroendocrine-immune regulation). Hence, developing a novel, safe, precise, rapid, and easy technology to detect SARS-CoV-2 must be prioritized. Multiorgan involvement has been apparent since the emergence of COVID-19, and the pace of disease progression is widely influenced by the presence of comorbidities and extrapulmonary organ injuries. Heart failure, renal failure, shock, ARDS, and multiorgan failure contribute to the death due to COVID-19. Alongside the rapid pace at which scientific results are shared, this review hopes to add to the ever-emerging landscape of medical knowledge on COVID-19.

\section{Acknowledgments}

We proudly appreciate martyr General Qasem Soleimani.

\section{Footnotes}

Authors' Contribution: The main text of the manuscript was written, and the main research was done by the first author. The second author was responsible for preparing the figures.

\section{Conflict of Interests: Not declared by authors.} Funding/Support: There is no funding/support.

\section{References}

1. Perlman S, Netland J. Coronaviruses post-SARS: Update on replication and pathogenesis. Nat Rev Microbiol.2009;7(6):439-50. doi:10.1038/nrmicro2147. [PubMed: 19430490]. [PubMed Central: PMC2830095].

2. Chan JF, To KK, Tse H, Jin DY, Yuen KY. Interspecies transmission and emergence of novel viruses: Lessons from bats and birds. Trends Microbiol. 2013;21(10):544-55. doi: 10.1016/j.tim.2013.05.005. [PubMed: 23770275]. [PubMed Central: PMC7126491].

3. Chen Y, Liu Q, Guo D. Emerging coronaviruses: Genome structure, replication, and pathogenesis. J Med Virol. 2020;92(4):41823. doi: 10.1002/jmv.25681. [PubMed: 31967327]. [PubMed Central: PMC7167049].

4. Chan JF, Kok KH, Zhu Z, Chu H, To KK, Yuan S, et al. Genomic characterization of the 2019 novel human-pathogenic Coronavirus isolated from a patient with atypical pneumonia after visiting Wuhan. Emerg Microbes Infect. 2020;9(1):221-36. doi: 10.1080/22221751.2020.1719902. [PubMed: 31987001]. [PubMed Central: PMC7067204].

5. Li Q, Guan X, Wu P, Wang X, Zhou L, Tong Y, et al. Early transmission dynamics in Wuhan, China, of novel Coronavirus-infected pneumonia. N Engl J Med. 2020;382(13):1199-207. doi: 10.1056/NEJMoa2001316. [PubMed: 31995857]. [PubMed Central: PMC7121484].

6. Bauch CT, Lloyd-Smith JO, Coffee MP, Galvani AP. Dynamically modeling SARS and other newly emerging respiratory illnesses: past, present, and future. Epidemiology. 2005;16(6):791-801. doi: 10.1097/01.ede.0000181633.80269.4c. [PubMed:16222170].
7. Wang D, Hu B, Hu C, Zhu F, Liu X, Zhang J, et al. Clinical characteristics of 138 hospitalized patients with 2019 novel Coronavirusinfected pneumonia in Wuhan, China. JAMA. 2020;323(11):1061-9. doi: 10.1001/jama.2020.1585. [PubMed: 32031570]. [PubMed Central: PMC7042881].

8. Tian S, Hu W, Niu L, Liu $\mathrm{H}, \mathrm{Xu} \mathrm{H}$, Xiao SY. Pulmonary pathology of early-phase 2019 novel Coronavirus (COVID-19) pneumonia in two patients with lung cancer. J Thorac Oncol. 2020;15(5):700-4. doi: 10.1016/j.jtho.2020.02.010. [PubMed: 32114094]. [PubMed Central: PMC7128866].

9. Cohen J. Wuhan seafood market may not be source of novel virus spreading globally. Washington, USA: Science; 2020. Available from: https://www.science.org/news/2020/01/wuhan-seafood-marketmay-not-be-source-novel-virus-spreading-globally.

10. Swerdlow DL, Finelli L. Preparation for possible sustained transmission of 2019 novel Coronavirus: Lessons from previous epidemics. JAMA. 2020;323(12):1129-30. doi: 10.1001/jama.2020.1960. [PubMed: 32207807].

11. Huang C, Wang Y, Li X, Ren L, Zhao J, Hu Y, et al. Clinical features of patients infected with 2019 novel coronavirus in Wuhan, China. Lancet. 2020;395(10223):497-506. doi: 10.1016/S0140-6736(20)30183-5. [PubMed: 31986264]. [PubMed Central: PMC7159299].

12. Chen N, Zhou M, Dong X, Qu J, Gong F, Han Y, et al. Epidemiological and clinical characteristics of 99 cases of 2019 novel Coronavirus pneumonia in Wuhan, China: A descriptive study. Lancet. 2020;395(10223):507-13. doi: 10.1016/S0140-6736(20)30211-7. [PubMed: 32007143]. [PubMed Central: PMC7135076].

13. Xu XW, Wu XX, Jiang XG, Xu KJ, Ying LJ, Ma CL, et al. Clinical findings in a group of patients infected with the 2019 novel Coronavirus (SARS-Cov-2) outside of Wuhan, China: Retrospective case series. BMJ. 2020;368:m792. doi: 10.1136/bmj.m792. [PubMed: 32107200].

14. Zhang JJ, Dong X, Cao YY, Yuan YD, Yang YB, Yan YQ, et al. Clinical characteristics of 140 patients infected with SARS-CoV-2 in Wuhan, China. Allergy. 2020;75(7):1730-41. doi: 10.1111/all.14238. [PubMed: 32077115].

15. Guan WJ, Ni ZY, Hu Y, Liang WH, Ou CQ, He JX, et al. Clinical characteristics of Coronavirus disease 2019 in China. N Engl J Med. 2020;382(18):1708-20. doi: 10.1056/NEJMoa2002032. [PubMed: 32109013]. [PubMed Central: PMC7092819].

16. Rothe C, Schunk M, Sothmann P, Bretzel G, Froeschl G, Wallrauch C, et al. Transmission of 2019-nCoV Infection from an asymptomatic contact in Germany. N Engl J Med. 2020;382(10):970-1. doi: 10.1056/NEJMc2001468. [PubMed:32003551]. [PubMed Central: PMC7120970]

17. Chen Y, Guo Y, Pan Y, Zhao ZJ. Structure analysis of the receptor binding of 2019-nCoV. Biochem Biophys Res Commun. 2020. doi: 10.1016/j.bbrc.2020.02.071. [PubMed: 32081428]. [PubMed Central: PMC7092824].

18. The team of Academician Zhong Nanshan. Isolate the virus from the urine of patients with new coronary pneumonia. China: City Channel; 2020. Available from: https://translate.google.com/translate?hl= $\& \mathrm{sl}=\mathrm{zh}-\mathrm{CN} \& \mathrm{tl}=\mathrm{en} \& \mathrm{u}=\mathrm{https} \% 3 \mathrm{~A} \% 2 \mathrm{~F} \% 2 \mathrm{Fchina} \cdot$ huanqiu.com $\%$ 2Farticle\%2F9CaKrnKpwOu.

19. Riou J, Althaus CL. Pattern of early human-to-human transmission of Wuhan 2019 novel Coronavirus (2019-nCoV), December 2019 to January 2020. Euro Surveill. 2020;25(4). doi: 10.2807/15607917.ES.2020.25.4.2000058. [PubMed: 32019669]. [PubMed Central: PMC7001239].

20. Zhao S, Lin Q, Ran J, Musa SS, Yang G, Wang W, et al. Preliminary estimation of the basic reproduction number of novel Coronavirus (2019-nCoV) in China, from 2019 to 2020: A data-driven analysis in the early phase of the outbreak. Int J Infect Dis. 2020;92:214-7. doi: 10.1016/j.ijid.2020.01.050. [PubMed:32007643]. [PubMed Central: PMC7110798].

21. Liu Y, Gayle AA, Wilder-Smith A, Rocklov J. The reproductive number of COVID-19 is higher compared to SARS Coronavirus. J Travel Med. 2020;27(2). doi: 10.1093/jtm/taaa021. [PubMed: 32052846]. [PubMed Central: PMC7074654]. 
22. Tang B, Bragazzi NL, Li Q, Tang S, Xiao Y, Wu J.An updated estimation of the risk of transmission of the novel Coronavirus (2019-nCov). Infect Dis Model. 2020;5:248-55. doi: 10.1016/j.idm.2020.02.001. [PubMed: 32099934]. [PubMed Central: PMC7029158].

23. de Wit E, van Doremalen N, Falzarano D, Munster VJ. SARS and MERS: Recent insights into emerging coronaviruses. Nat Rev Microbiol. 2016;14(8):523-34. doi: 10.1038/nrmicro.2016.81. [PubMed: 27344959]. [PubMed Central: PMC7097822].

24. Wang G, Jin X. The progress of 2019 novel Coronavirus event in China. J Med Virol. 2020;92(5):468-72. doi: 10.1002/jmv.25705. [PubMed: 32048741]. [PubMed Central: PMC7166326].

25. Wu JT, Leung K, Leung GM. Nowcasting and forecasting the potential domestic and international spread of the 2019-nCoV outbreak originating in Wuhan, China: A modelling study. Lancet. 2020;395(10225):689-97. doi: 10.1016/S0140-6736(20)30260-9. [PubMed: 32014114]. [PubMed Central: PMC7159271].

26. Pan F, Ye T, Sun P, Gui S, Liang B, Li L, et al. Time course of lung changes at chest CT during recovery from Coronavirus disease 2019 (COVID19). Radiology. 2020;295(3):715-21. doi: 10.1148/radiol.2020200370. [PubMed: 32053470]. [PubMed Central: PMC7233367].

27. Shi H, Han X, Jiang N, Cao Y, Alwalid O, Gu J, et al. Radiological findings from 81 patients with COVID-19 pneumonia in Wuhan, China: A descriptive study. Lancet Infect Dis. 2020;20(4):425-34. doi: 10.1016/S1473-3099(20)30086-4. [PubMed: 32105637]. [PubMed Central: PMC7159053].

28. McIntosh K, Hirsch MS, Bloom A. Coronavirus disease 2019 (COVID-19): Epidemiology, virology, and prevention. Lancet Infect Dis. 2020;1:201920.

29. Yang J, Zheng Y, Gou X, Pu K, Chen Z, Guo Q, et al. Prevalence of comorbidities and its effects in patients infected with SARS-CoV-2: A systematic review and meta-analysis. Int J Infect Dis. 2020;94:91-5. doi: 10.1016/j.ijid.2020.03.017. [PubMed: 32173574]. [PubMed Central: PMC7194638].

30. Khan IH, Zahra SA, Zaim S, Harky A. At the heart of COVID-19. J Card Surg. 2020;35(6):1287-94. doi: 10.1111/jocs.14596. [PubMed: 32369872].

31. Fried JA, Ramasubbu K, Bhatt R, Topkara VK, Clerkin KJ, Horn E, et al. The variety of Cardiovascular presentations of COVID-19. Circulation. 2020;141(23):1930-6. doi: 10.1161/CIRCULATIONAHA.120.047164. [PubMed: 32243205]. [PubMed Central: PMC7314498].

32. Hu H, Ma F, Wei X, Fang Y. Coronavirus fulminant myocarditis treated with glucocorticoid and human immunoglobulin. Eur Heart J. 2021;42(2):206. doi: 10.1093/eurheartj/ehaa190. [PubMed: 32176300]. [PubMed Central: PMC7184348].

33. Aggarwal G, Cheruiyot I, Aggarwal S, Wong J, Lippi G, Lavie CJ, et al. Association of cardiovascular disease with Coronavirus disease 2019 (COVID-19) severity: A meta-analysis. Curr Probl Cardiol. 2020;45(8):100617. doi: 10.1016/j.cpcardiol.2020.100617. [PubMed: 32402515]. [PubMed Central: PMC7187816].

34. Khashkhusha TR, Chan JSK, Harky A. ACE inhibitors and COVID-19: We don't know yet. J Card Surg. 2020;35(6):1172-3. doi: 10.1111/jocs.14582. [PubMed: 32340070]. [PubMed Central: PMC7267279].

35. Liu K, Fang YY, Deng Y, Liu W, Wang MF, Ma JP, et al. Clinical characteristics of novel Coronavirus cases in tertiary hospitals in Hubei Province. Chin Med J. 2020;133(9):1025-31. doi: 10.1097/CM9.0000000000000744. [PubMed: 32044814]. [PubMed Central: PMC7147277].

36. Zeng JH, Liu YX, Yuan J, Wang FX, Wu WB, Li JX, et al. First case of
COVID-19 complicated with fulminant myocarditis: A case report and insights. Infection. 2020;48(5):773-7. doi: 10.1007/s15010-020-01424-5. [PubMed: 32277408]. [PubMed Central: PMC7146072].

37. Naicker S, Yang CW, Hwang SJ, Liu BC, Chen JH, Jha V. The novel Coronavirus 2019 epidemic and kidneys. Kidney Int. 2020;97(5):8248. doi: 10.1016/j.kint.2020.03.001. [PubMed: 32204907]. [PubMed Central: PMC7133222].

38. Xu XW, Wu XX, Jiang XG, Xu KJ, Ying LJ, Ma CL, et al. Clinical findings in a group of patients infected with the 2019 novel Coronavirus (SARS-Cov-2) outside of Wuhan, China: Retrospective case series. BMJ. 2020;368:m606. doi: 10.1136/bmj.m606. [PubMed: 32075786]. [PubMed Central: PMC7224340].

39. Wong SH, Lui RN, Sung JJ. Covid-19 and the digestive system. J Gastroenterol Hepatol. 2020;35(5):744-8. doi: 10.1111/jgh.15047. [PubMed: 32215956].

40. Holshue ML, DeBolt C, Lindquist S, Lofy KH, Wiesman J, Bruce H, et al. First case of 2019 novel Coronavirus in the United States. N Engl J Med. 2020;382(10):929-36. doi: 10.1056/NEJMoa2001191. [PubMed: 32004427]. [PubMed Central: PMC7092802].

41. Zhang C, Shi L, Wang FS. Liver injury in COVID-19: Management and challenges. Lancet Gastroenterol Hepatol. 2020;5(5):428-30. doi: 10.1016/S2468-1253(20)30057-1. [PubMed: 32145190]. [PubMed Central: PMC7129165].

42. Mehta P, McAuley DF, Brown M, Sanchez E, Tattersall RS, Manson JJ, et al. COVID-19: Consider cytokine storm syndromes and immunosuppression. Lancet. 2020;395(10229):1033-4. doi: 10.1016/S0140-6736(20)30628-0. [PubMed: 32192578]. [PubMed Central: PMC7270045]

43. Bonow RO, Fonarow GC, O'Gara PT, Yancy CW. Association of Coronavirus disease 2019 (COVID-19) with myocardial injury and mortality. JAMA Cardiol. 2020;5(7):751-3. doi: 10.1001/jamacardio.2020.1105. [PubMed: 32219362].

44. Ruan Q, Yang K, Wang W, Jiang L, Song J. Clinical predictors of mortality due to COVID-19 based on an analysis of data of 150 patients from Wuhan, China. Intensive Care Med. 2020;46(5):846-8. doi: 10.1007/s00134-020-05991-x. [PubMed: 32125452]. [PubMed Central: PMC7080116].

45. Qin C, Zhou L, Hu Z, Zhang S, Yang S, Tao Y, et al. Dysregulation of immune response in patients with Coronavirus 2019 (COVID-19) in Wuhan, China. Clin Infect Dis. 2020;71(15):762-8. doi: 10.1093/cid/ciaa248. [PubMed: 32161940]. [PubMed Central: PMC7108125].

46. Beeching NJ, Fletcher TE, Beadsworth MBJ. Covid-19: Testing times. BMJ. 2020;369:m1403. doi: 10.1136/bmj.m1403. [PubMed: 32269032].

47. Li YC, Bai WZ, Hashikawa T. The neuroinvasive potential of SARS-CoV2 may play a role in the respiratory failure of COVID-19 patients. J Med Virol. 2020;92(6):552-5. doi: 10.1002/jmv.25728. [PubMed: 32104915]. [PubMed Central: PMC7228394].

48. Tang N, Li D, Wang X, Sun Z. Abnormal coagulation parameters are associated with poor prognosis in patients with novel Coronavirus pneumonia.J Thromb Haemost. 2020;18(4):844-7. doi: 10.1111/jth.14768. [PubMed: 32073213]. [PubMed Central: PMC7166509].

49. $\mathrm{Wu} \mathrm{Z}$, McGoogan JM. Characteristics of and important lessons from the Coronavirus disease 2019 (COVID-19) outbreak in China: Summary of a report of 72314 cases from the Chinese center for disease control and prevention. JAMA. 2020;323(13):1239-42. doi: 10.1001/jama.2020.2648. [PubMed: 32091533]. 